\title{
Effects of San'o-shashin-to and the Constituent Herbal Medicines on Theophylline-Induced Increase in Arterial Blood Pressure of Rats
}

\author{
Fujiko Sanae, ${ }^{*}, a$ Yasuhiro Komatsu, ${ }^{b}$ Keigo ChisaKi, ${ }^{c}$ Toshitaka KIdo, ${ }^{c}$ Atsushi Ishige, ${ }^{c}$ and \\ Hisao HAYASHI ${ }^{a}$ \\ Department of Medicine, Faculty of Pharmaceutical Sciences, Hokuriku University, ${ }^{a}$ Ho-3 Kanagawa-machi, Kanazawa \\ 920-1181, Japan, Department of Serology, Kanazawa Medical University, ${ }^{b}$ 1-1 Daigaku, Uchinada-machi, Kahoku-gun, \\ Ishikawa 920-0293, Japan, and Central Research Laboratories, Tsumura \& Co., ${ }^{c} 3586$ Yoshiwara, Ami-machi, Inashiki- \\ gun, Ibaraki 300-1192, Japan. Received April 20, 2001; accepted July 8, 2001
}

\begin{abstract}
San'o-shashin-to, composed of Scutellariae Radix, Coptidis Rhizoma and Rhei Rhizoma (volume ratio= $1: 1: 1)$, reduced an increase in arterial blood pressure of anesthetized rats induced by theophylline $(5 \mathrm{mg} / \mathrm{kg}$, i.v.). The hypotensive effect of San'o-shashin-to was produced in a dose dependent manner and was maximum at its $0.5 \mathrm{~g} / \mathrm{kg}$. Then the constituent herbal medicines were examined for their possible hypotensive effect. Scutellariae Radix of $0.2 \mathrm{~g} / \mathrm{kg}$ slightly decreased in the blood presure. Rhei Rhizoma of $0.2 \mathrm{~g} / \mathrm{kg}$ decreased in the blood pressure and the hypotensive effect was significantly produced even at the dose of $0.05 \mathrm{~g} / \mathrm{kg}$, while Coptidis Rhizoma had little effect. Among fractions of San'o-shashin-to separated by Diaion HP-20 column chromatography, the $50 \%$ methanol-eluted fraction had a large hypotensive effect. The $50 \%$ methanol-eluted fraction of Scutellariae Radix and Rhei Rhizoma were also effective and, especially, that of Rhei Rhizoma had a large hypotensive effect. In isometric tension study, Scutellariae Radix and Rhei Rhizoma $(10-30 \mu \mathrm{g} / \mathrm{ml})$ slightly exerted contractile and relaxant effects, respectively, on the phenylephrine-contracted endothelium-intact rat thoracic aorta. Coptidis Rhizoma $(1-10 \mu \mathrm{g} / \mathrm{ml})$ caused both endothelium-dependent and -independent relaxantion. These results suggest that the hypotensive effect of San'o-shashin-to is not mediated by the direct action on blood vessel but by other actions. Some components in Scutellariae Radix and Rhei Rhizoma, especially in the latter may play a main role in the hypotensive effect.
\end{abstract}

Key words San'o-shashin-to; hypotensive effet; Rhei Rhizoma; Scutellariae Radix; Coptidis Rhizoma; theophylline

Some Kampo medicines including San'o-shashin-to are clinically used to treat hypertension and the various simultaneous symptoms. However, the pharmacological basis for the ameliorative effects of the Kampo medicines on cardiovascular systems are poorly understood. The appropriate prescription is chosen according to the specific conditions of each patient in the system of Kampo.

We have previously examined the effects of 9 kinds of Kampo medicines, which are clinically used for the treatment of hypertension, on anesthetized rats with increase in arterial blood pressure induced by theophylline. This survey elucidated that Saiko-ka-ryukotsu-borei-to, Oren-gedoku-to, San'o-shashin-to and Dai-jyoki-to among 9 Kampo medicines have hypotensive effects. ${ }^{1)}$ These Kampo medicines are clinically used to treat considerably or relatively strong patients with symptoms such as feeling of uprising heat, restlessness, insomnia, irritability and psychic symptoms. Since Kampo medicines are blended herbal medicines composed of several crude drugs that may possess complex interactions, it is generally uncertain which crude drugs are responsible for their biological actions. However, 4 Kampo medicines mentioned above have Scutellariae Radix and/or Rehi Rhizoma as a common constituent(s). Scutellariae Radix and/or Rehi Rhizoma might play a main role for suppressions on theophylline-induced increase in arterial blood pressure by these Kampo medicines. With respect to the hypotensive effect of Oren-gedoku-to, Higasa et al. $^{2)}$ demonstrated a participation of the vasorelaxat effect of Scutellariae Radix and Rehi Rhizoma. San'o-shashin-to is composed of Scutellariae Radix, Coptidis Rhizoma and Rhei Rhizoma (volume rate=1:1:1). In this study, we examined the constituent herbal medicines of San'o-shashin-to for their possible hypotensive effect using theophylline-treated rats, ${ }^{3)}$ and then the effects of fractions of San'o-shashin-to separated by column chromatography were examined to search the main substance caused hypotesive effect. Moreover, we examined the vascular effects of San'o-shashin-to and its 3 constituent herbal medicines on rat thoracic aorta and compared with their presence of hypotensive effects.

\section{MATERIALS AND METHODS}

Materials Theophylline (Wako Pure Chemical Ind., Ltd., Osaka), L-phenylephrine hydrochloride (Tokyo Kasei, Tokyo), acetycholine chloride (Ovisot ${ }^{\mathrm{TM}}$, Daiichi Pharmaceutical Co., Tokyo) were purchased. San'o-shashin-to, Scutellariae Radix, Coptidis Rhizoma and Rhei Rhizoma are powder of hot water-extracts of natural products by Tsumura \& Co.

Fractionation of San'o-shashin-to and the Constituent Medicines The San'o-shashin-to extract was subjected to the column chromatography of Diaion HP-20 (Mitsubishi Chemical, Tokyo) and fractionated as shown in Fig. 1. The extract $(100 \mathrm{~g})$ was separated into three fractions, Fraction A $(21.7 \mathrm{~g})$, Fraction B (28.9 g) and Fraction C (10.2 g), by column chromatography. Fractionations of Scutellariae Radix, Coptidis Rhizoma and Rhei Rhizoma were done in the same manner. Scutellariae Radix Fraction B (15.5 g), Coptidis Rhizoma Fraction B (18.8 g) and Rhei Rhizoma Fraction B $(10.5 \mathrm{~g})$ were separated from each medicine $(50 \mathrm{~g})$.

Measurements of Blood Pressure and Heart Rate in Rats Male Wistar rats (Nihon SLC, Inc., Hamamatsu) weighing $240-280 \mathrm{~g}$ were used. After being starved for $18-22 \mathrm{~h}$ before experiments, rats were anesthetized with 


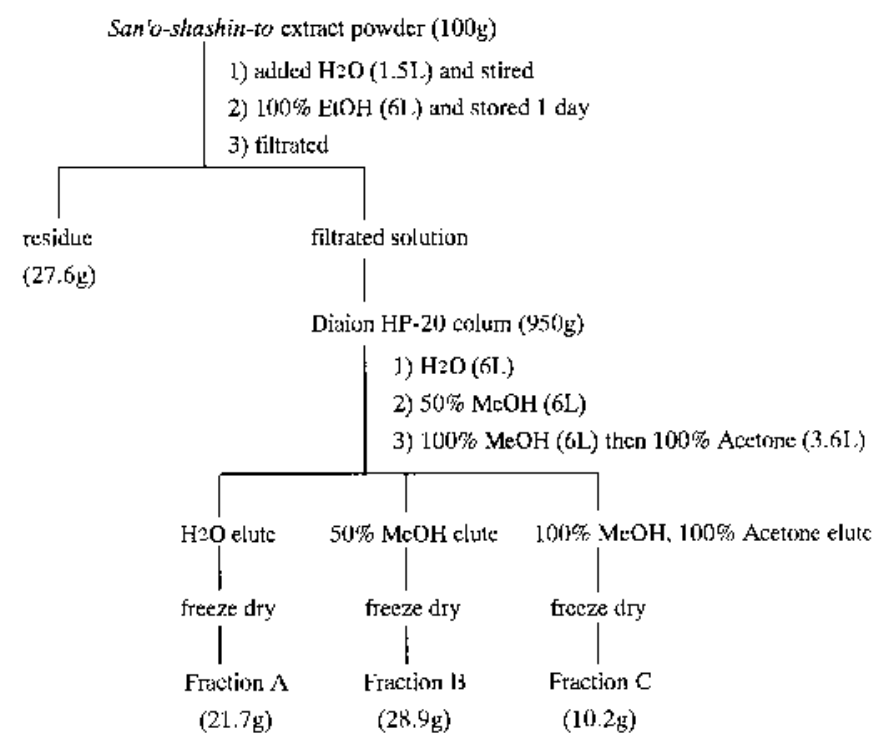

Fig. 1. Fractionation Protocol of the San'o-shashin-to Extract

urethane $(800 \mathrm{mg} / \mathrm{kg}$, i.p., supplemented as required) and $\alpha$ chloralose $(80 \mathrm{mg} / \mathrm{kg}$, i.p.). A cannula was inserted into the duodenum from stomach for San'o-shashin-to and other extracts administration. The left carotid artery and vein were catheterized for blood pressure measurement and intravenous injections, respectively. Blood pressure and heart rate were monitored continuously with a pressure transducer (MP5200; Baxter, Tokyo) and recorded on a recorder (WR3701; Graphtec, Yokohama). The heart rate was counted with a cardiotachometer (AT-601G; Nihon Kohden Co., Tokyo) triggered by blood pressure pulses. The experimental procedure started after an at least 30-min resting period for stabilization of blood pressure and heart rate. Theophylline was dissolved in saline and injected intravenously as a bolus of $5 \mathrm{mg} / \mathrm{kg}$ to the rats. Subjects including San'o-shashin-to, which were suspended in saline containing $0.5 \%$ carboxymethylcellulose, were administered intraduodenally (i.d.) to rats $15 \mathrm{~min}$ after injection of theophylline, according to the same method as described in our previous paper. ${ }^{1)}$ No effect of the vehicle volume on the hemodynamics was observed in anesthetized rats.

Isometric Tension Studies in Rat Aorta Male Wistar rats weighing 300-350g (Nihon SLC, Inc., Hamamatsu) were killed by being stunned and bled. The thoracic aorta was removed and carefully cleaned of adhering fat and connective tissue, and cut into helical strips (approx. $2.5 \mathrm{~mm} \times$ $20 \mathrm{~mm}$ length). The strips were then mounted in standard organ baths filled with Krebs-Henseleit solution (composition in mM: $\mathrm{NaCl} 118, \mathrm{KCl} 4.7, \mathrm{CaCl}_{2} \cdot 2 \mathrm{H}_{2} \mathrm{O} 2.55, \mathrm{MgSO}_{4}$. $7 \mathrm{H}_{2} \mathrm{O} 1.18, \mathrm{KH}_{2} \mathrm{PO}_{4} 1.18$, glucose 11.1 and $\mathrm{NaHCO}_{3} 24.88$ ), maintained at $37^{\circ} \mathrm{C}$ and continuously bubbled with a $95 \% \mathrm{O}_{2}-5 \% \mathrm{CO}_{2}$ mixture. Resting tension was adjusted to $1 \mathrm{~g}$. Tension was measured with an isometric force transducer. After an equilibration period of $90 \mathrm{~min}$, the strips were maximally contacted with phenylephrine $(1 \mu \mathrm{M})$ in order to test their contractile capacity. In some experiments, the endothelium was removed by gently rubbing the internal surface with a filter paper. The presence of functional endothelium was assessed in all preparations by determining the ability of acetylcholine $(1 \mu \mathrm{M})$ to induce more than $50 \%$ relaxation of strips pre-contracted with phenylephrine $(0.1 \mu \mathrm{M})$. Vessels were considered to be denuded functional endothelium when there was no relaxation response to acetylcholine. Aortic strips with and without functional endothelium were precontracted to approximately $80 \%$ of maximal tension by 0.1 or $0.03 \mu \mathrm{M}$ phenylephrine, respectively. After the phenylephrine-induced contraction were sustained, San'o-shashin-to or the each constituent medicine was added cumulatively.

Statistical Analysis Results are expressed as the mean \pm S.E. The statistical analysis of difference was done by Dunnett's test for multiple comparisons. Differences were accepted as statistically significant at $p$-values $<0.05$.

\section{RESULTS}

Effects of San'o-shashin-to and the Constituent Medicines on Blood Pressure and Heart Rate in TheophyllineTreated Rats A bolus injection of theophylline $(5 \mathrm{mg} / \mathrm{kg}$, i.v.) produced a rise in arterial blood pressure, with increases in heart rate of anesthetized rats. These increased variables after $15 \mathrm{~min}$ were significantly different from the pre-treatment values and remained for at least $60 \mathrm{~min}$. Subsequent administration of San'o-shashin-to $(1.0,0.5,0.25 \mathrm{~g} / \mathrm{kg}$, i.d.) after theophylline injection caused a reduction in mean arterial blood pressure but did not in heart rate so that values of mean arterial blood pressure $30-60 \mathrm{~min}$ after the administration were significanly different from the values produced by no further medicine after theophylline injection. The hypotensive effect was produced in a dose-dependent manner and maximum at its $0.5 \mathrm{~g} / \mathrm{kg}$ (Fig. 2a). It seems that $1.0 \mathrm{~g}$ and $0.5 \mathrm{~g}$ of San'o-shashin-to contain about $0.35 \mathrm{~g}$ and $0.2 \mathrm{~g}$, respectively, of each constituent medicine. The effects of 0.35 and $0.2 \mathrm{~g} / \mathrm{kg}$ of each medicine on mean arterial blood pressure in theophylline-treated rats are shown in Fig. 2b. Subsequent administration of $0.35 \mathrm{~g} / \mathrm{kg}$ of Scutellariae Radix caused a reduction in mean arterial blood pressure, but the $0.2 \mathrm{~g} / \mathrm{kg}$ administration had little effect. The administration of 0.35 or $0.2 \mathrm{~g} / \mathrm{kg}$ of Coptidis Rhizoma had not so hypotensive effect. Rhei Rhizoma reduced the theophylline-induced increase in mean arterial blood pressure in a dose-dependent manner and the hypotensive effect was maximum at $0.1 \mathrm{~g} / \mathrm{kg}$. The effect was significantly caused even at $0.05 \mathrm{~g} / \mathrm{kg}$. The administration of $0.2 \mathrm{~g} / \mathrm{kg}$ of Rhei Rhizoma reduced in heart rate of theophylline-treated rats slowly, but not significantly.

San'o-shashin-to $(0.5 \mathrm{~g} / \mathrm{kg})$, Scutellariae Radix $(0.2 \mathrm{~g} / \mathrm{kg})$, Coptidis Rhizoma $(0.2 \mathrm{~g} / \mathrm{kg})$ and Rhei Rhizoma $(0.2 \mathrm{~g} / \mathrm{kg})$ had no influence on arterial blood pressure or heart rate in theophylline-nontreated rats (data not shown).

Effects of Fractions of San'o-shashin-to and the Constituent Medicines on Blood Pressure and Heart Rate in Theophylline-Treated Rats Effect of each fraction on mean arterial blood pressure is shown in Fig. 3. The dose of three fractions examined (Fraction A, $0.1 \mathrm{~g} / \mathrm{kg}$; Fraction B, $0.15 \mathrm{~g} / \mathrm{kg}$; Fraction $\mathrm{C}, 0.05 \mathrm{~g} / \mathrm{kg}$ ) were roughly calculated from their extraction ratio and $0.5 \mathrm{~g} / \mathrm{kg}$ of San'o-shashin-to that caused maximum hypotensive effect. Fraction A of $0.1 \mathrm{~g} / \mathrm{kg}$ had little influence, whereas Fraction B of $0.15 \mathrm{~g} / \mathrm{kg}$ caused a significant reduction in mean arterial blood pressure 15-60 min after the administration. Furthermote, even its half dose $(0.075 \mathrm{~g} / \mathrm{kg})$ administration showed the same effect 
a)

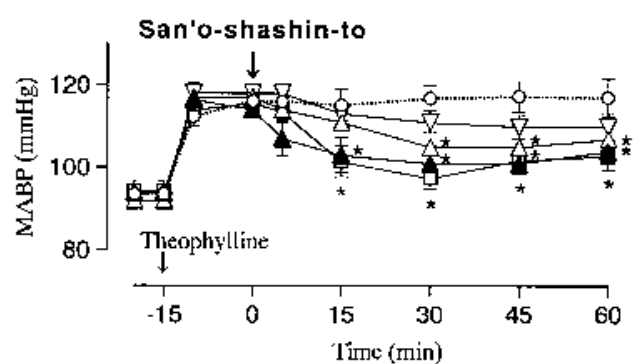

b)
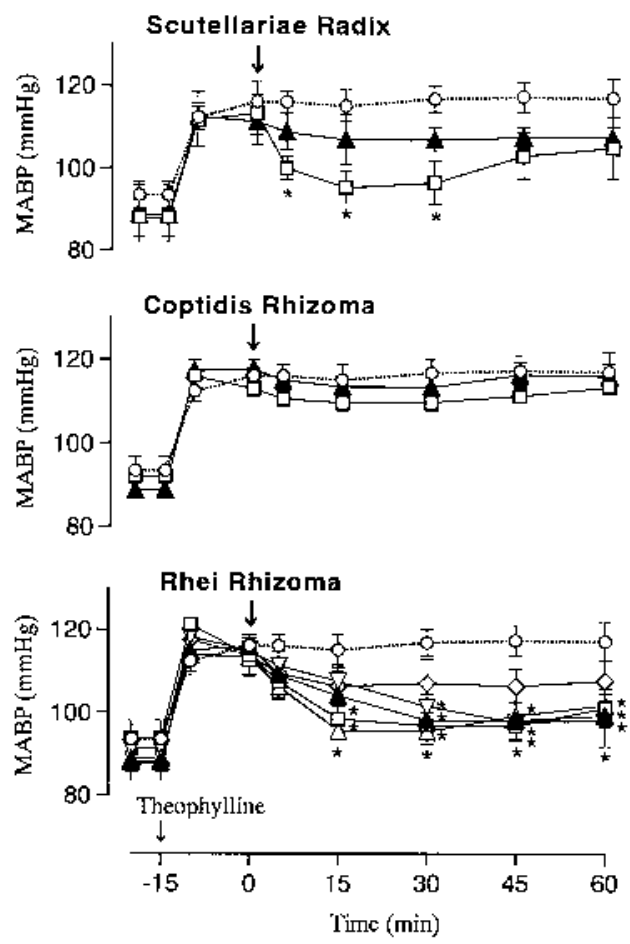

Fig. 2. Effects of San'o-shashin-to (a) and the Constituent Medicines (b) on Theophylline-Induced Increases in Mean Arterial Blood Pressure in Anesthetized Rats

San'o-shashin-to of $1.0 \mathrm{~g} / \mathrm{kg}(\square), 0.5 \mathrm{~g} / \mathrm{kg}(\mathbf{\Delta}), 0.025 \mathrm{~g} / \mathrm{kg}(\triangle)$ and $0.125 \mathrm{~g} / \mathrm{kg}(\nabla)$, Scutellariae Radix and Coptidis Rhizoma of $0.35 \mathrm{~g} / \mathrm{kg}(\square)$ and $0.2 \mathrm{~g} / \mathrm{kg}(\boldsymbol{\Delta})$, Rhei Rhizoma of $0.35 \mathrm{~g} / \mathrm{kg}(\square), 0.2 \mathrm{~g} / \mathrm{kg}(\boldsymbol{\Delta}), 0.1 \mathrm{~g} / \mathrm{kg}(\triangle), 0.05 \mathrm{~g} / \mathrm{kg}(\nabla)$ and $0.025 \mathrm{~g} / \mathrm{kg}(\diamond)$ or vehicle $(\bigcirc)$ was intraduodenaly administered to rats $15 \mathrm{~min}$ after injection of theophylline $(5 \mathrm{mg} / \mathrm{kg}$, i.v.). Values of mean arterial blood pressure at $0 \mathrm{~min}$ are significantly different from their theophylline pre-treatment values. Each point represents the mean \pm S.E. of $4-7$ rats. $* p<0.05 v s$. control rats.

and the efficacy was equal to that of $0.15 \mathrm{~g} / \mathrm{kg}$. Fraction $\mathrm{C}$ of $0.05 \mathrm{~g} / \mathrm{kg}$ caused a significant reduction in mean arterial blood pressure 15-60 min after the administration, but $0.025 \mathrm{~g} / \mathrm{kg}$ had litle effect. On theophylline-induced increase in heart rate, Fraction A had no influence, but Fraction B and Fraction C slowly and slightly reduced (data not shown).

Effects of Scutellariae Radix Fraction B, Coptidis Rhizoma Fraction B and Rhei Rhizoma fraction B on theophylline-induced increase in mean arterial blood pressure are shown in Fig. 4. Scutellariae Radix Fraction B of $0.5 \mathrm{~g} / \mathrm{kg}$ caused a reduction in mean arterial blood pressure, although the hypotensive effect was small. Coptidis Rhizoma Fraction B of $0.5 \mathrm{~g} / \mathrm{kg}$ had little effect. Rhei Rhizoma Fraction B of 0.5 and $0.025 \mathrm{~g} / \mathrm{kg}$ caused a significant reduction in blood pressure, with a slow and slight reduction in heart rate, and $0.0125 \mathrm{~g} / \mathrm{kg}$ also caused a slight reduction in blood pressure.

All of Fraction A $(0.1 \mathrm{~g} / \mathrm{kg})$, Fraction B $(0.15 \mathrm{~g} / \mathrm{kg})$, Frac-
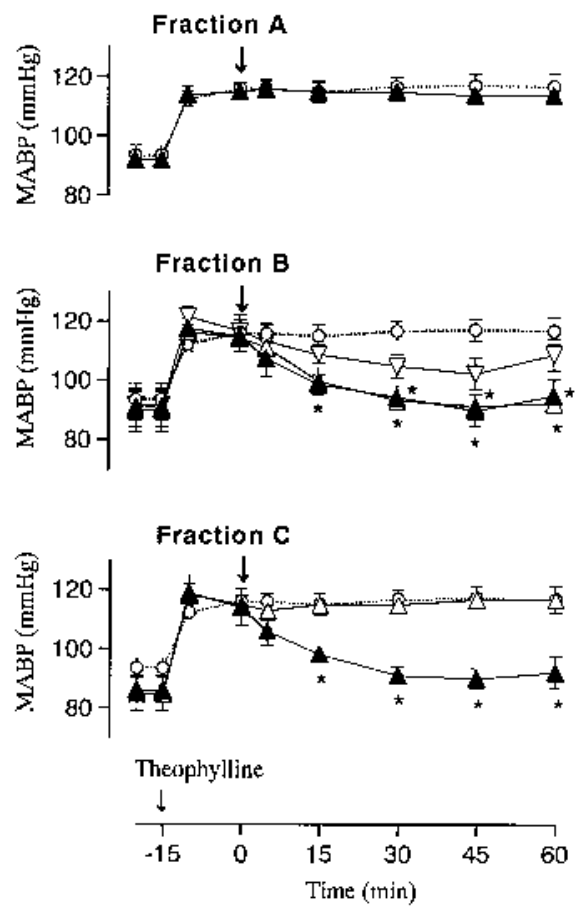

Fig. 3. Effects of Each Fraction Separated from San'o-shashin-to on Theophylline-Induced Increases in Mean Arterial Blood Pressure in Anesthetized Rats

Fraction A of $0.1 \mathrm{~g} / \mathrm{kg}(\mathbf{\Lambda})$, Fraction B of $0.15 \mathrm{~g} / \mathrm{kg}(\mathbf{\Lambda}), 0.075 \mathrm{~g} / \mathrm{kg}(\triangle)$ and $0.04 \mathrm{~g} / \mathrm{kg}$ $(\nabla)$, Fraction $\mathrm{C}$ of $0.05 \mathrm{~g} / \mathrm{kg}(\boldsymbol{\Lambda})$ and $0.025 \mathrm{~g} / \mathrm{kg}(\triangle)$ or vehicle $(\mathrm{O})$ was intraduodenaly administered to rats $15 \mathrm{~min}$ after injection of theophylline $(5 \mathrm{mg} / \mathrm{kg}$, i.v.). Each point represents the mean \pm S.E. of 4 or 5 rats. $* p<0.05 v$ s. control rats.
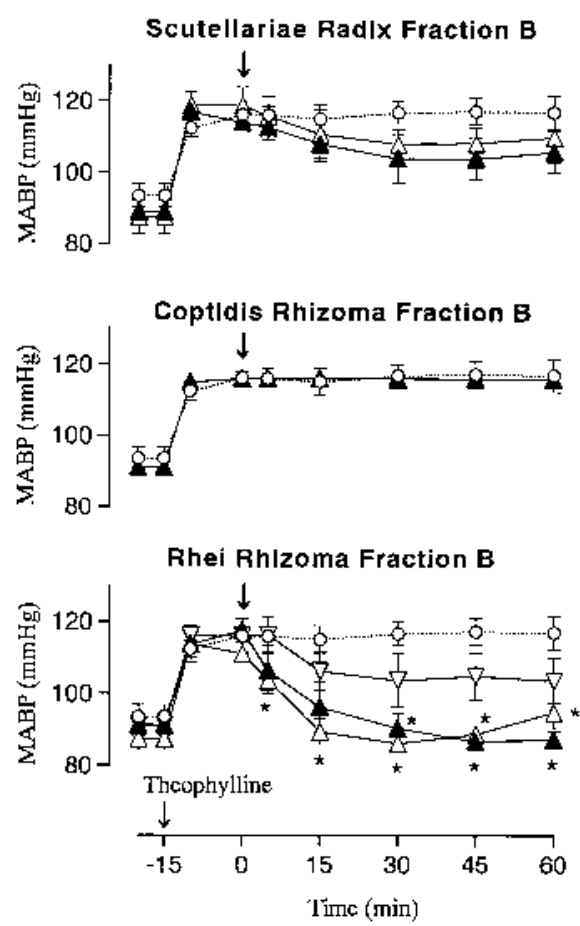

Fig. 4. Effects of 50\% Methanol-Eluted Fraction (Fraction B) from Scutellariae Radix, Coptidis Rhizoma and Rhei Rhizoma on TheophyllineInduced Increases in Mean Arterial Blood Pressure in Anesthetized Rats

Scutellariae Radix Fraction B of $0.05 \mathrm{~g} / \mathrm{kg}(\mathbf{\Lambda})$ and $0.025 \mathrm{~g} / \mathrm{kg}(\triangle)$, Coptidis Rhizoma Fraction B of $0.05 \mathrm{~g} / \mathrm{kg}(\mathbf{\Lambda})$, Rhei Rhizoma Fraction B of $0.05 \mathrm{~g} / \mathrm{kg}(\mathbf{\Lambda})$, $0.025 \mathrm{~g} / \mathrm{kg}(\triangle)$ and $0.0125 \mathrm{~g} / \mathrm{kg}(\nabla)$ or vehicle $(\bigcirc)$ was intraduodenaly administered to rats $15 \mathrm{~min}$ after injection of theophylline $(5 \mathrm{mg} / \mathrm{kg}$, i.v.). Each point represents the mean \pm S.E. of 4 or 5 rats. $* p<0.05 v s$. control rats. 
a)

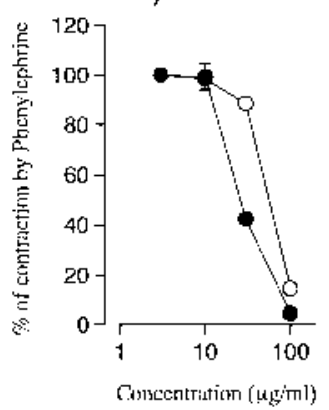

b)

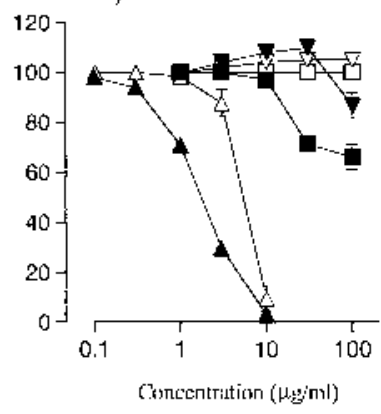

Fig. 5. Effects of San'o-shashin-to (a) and the Constituent Medicines (b) on Rat Thoracic Aorta Pre-Contracted by Phenylephrine

San'o-shashin-to $(\bullet, \bigcirc)$, Scutellariae Radix $(\boldsymbol{\nabla}, \nabla)$, Coptidis Rhizoma $(\boldsymbol{\Delta}, \triangle)$, or Rhei Rhizoma $(\boldsymbol{\square}, \square)$ was added cumulatively to endothelium-intact $(\boldsymbol{\bullet}, \boldsymbol{\nabla}, \boldsymbol{\Lambda}, \mathbf{\square})$ and -denuded $(\bigcirc, \nabla, \triangle, \square)$ aorta pre-contracted by phenylephrine of 0.1 and $0.03 \mu \mathrm{M}$, respectively. Values represent the mean \pm S.E. of 4 experiments. Where no error bar is shown, the error is smaller than the symbol.

tion C $(0.05 \mathrm{~g} / \mathrm{kg})$, Scutellariae Radix Fraction B $(0.05 \mathrm{~g} / \mathrm{kg})$, Coptidis Rhizoma Fraction B $(0.05 \mathrm{~g} / \mathrm{kg})$ and Rhei Rhizoma fraction $\mathrm{B}(0.05 \mathrm{~g} / \mathrm{kg})$ had little influence on arterial blood pressure and heart rate in theophylline-nontreated rats (data not shown).

Effects of San'o-shashin-to and the Constituent Medicines on the Phenylephrine-Contracted Rat Thoracic Aorta In endothelium-intact aorta, San'o-shashin-to produced a dose dependent relaxation and the ability at $30 \mu \mathrm{g} / \mathrm{ml}$ was more than $50 \%$ relaxation of aorta pre-contracted with phenylephrine. In endothelium-denuded aorta, San'o-shashinto also produced a relaxation, but the ability at $30 \mu \mathrm{g} / \mathrm{ml}$ was no more than $10 \%$ relaxation (Fig. 5a).

Scutellariae Radix produced two distinct effects in endothelium-intact aorta. In a lower concentration range (3$30 \mu \mathrm{g} / \mathrm{ml}$ ), Scutellariae Radix caused further contraction; the contracted aorta started to relax when the concentration of the medicine was increased over $100 \mu \mathrm{g} / \mathrm{ml}$. The contractile and relaxant responses to Scutellariae Radix nearly abolished in endothelium-denuded aorta. Coptidis Rhizoma produced a dose dependent relaxation in endothelium-intact and-denuded aorta pre-contracted with phenylephrine. The medicine below $3 \mu \mathrm{g} / \mathrm{ml}$ produced a significant relaxation in endothelium-intact aorta, but was not produced a similar relaxation in endothelium-denuded aorta. Rhei Rhizoma produced a relaxation in endothelium-intact aorta, but no more than $40 \%$ relaxation even at $100 \mu \mathrm{g} / \mathrm{ml}$. The relaxant response to Rhei Rhizoma abolished in endothelium-denuded aorta (Fig. $5 b)$.

\section{DISCUSSION}

We have previously suggested that Saiko-ka-ryukotsuborei-to, Oren-gedoku-to, San'o-shashin-to and Dai-jyoki-to are useful to treat hypertension in the sympathetic system dominance, and that Scutellariae Radix and/or Rhei Rhizoma might play a main role in those hypotensive effects, since these 4 Kampo medicines have Scutellariae Radix and/or Rhei Rhizoma as a common constituent(s). ${ }^{1)}$ In this study, effects of San'o-shashin-to and the constituent herbal medicines, Scutellariae Radix, Coptidis Rhizoma and Rhei Rhizoma, on theophylline-treated rats were examined. A bolus injection of theophylline $(5 \mathrm{mg} / \mathrm{kg}$, i.v. $)$ produced a rise in arterial blood pressure, with increases in heart rate. The theophylline-induced effect on arterial blood pressure and heart rate, which were attenuated by pre-treatment with reserpine, ${ }^{3}$ ) therefore, might be partially due to actions of the endogenous catecholamines on vascular smooth muscle and heart. As shown in previous report, ${ }^{1)}$ San'o-shashin-to reduced in arterial blood pressure in a dose dependent manner, and the hypotensive effect was maximum at $0.5 \mathrm{~g} / \mathrm{kg}$. Based on this dose of San'o-shashin-to, the possible hypotensive effect of the constituent medicines was investigated. Scutellariae Radix $(0.2 \mathrm{~g} / \mathrm{kg})$ slightly decreased in blood pressure, whereas $0.35 \mathrm{~g} / \mathrm{kg}$ caused a significant decrease in blood pressure. Rhei Rhizoma $(0.2 \mathrm{~g} / \mathrm{kg})$ significantly decreased in blood pressure. The hypotensive effect of Rhei Rhizoma was significantly caused even at the dose of $0.05 \mathrm{~g} / \mathrm{kg}$. While, Coptidis Rhizoma had little effect on blood pressure. These results confirmed our previous suggestion that Scutellariae Radix and/or Rhei Rhizoma may play a main role in the hypotensive effect of Kampo medicines on hypertension in the sympathetic system dominane.

Among fractions of San'o-shashin-to separated by Diaion HP-20 column chromatography, the 50\% methanol-eluted fraction (Fraction B) had a large hypotensive effect. Scutellariae Radix Fraction B and Rhei Rhizoma Fraction B were also effective, and the hypotensive effect of the former was more lager than that of the latter. While, Coptidis Rhizoma Fraction B had little effect. The water-eluted fraction of San'o-shashin-to had no effect. The $100 \%$ methanol, acetone-eluted fraction (Fraction $\mathrm{C}$ ) of the medicine had hypotensive effect as well as Fraction B of the Kampo medicine. These results suggest that the hypotensive effect of San'o-shashin-to is produced by some components contained in Scutellariae Radix and Rhei Rhizoma, and that some components in Rhei Rhizoma Fraction B may play a main role in the effect. Such components in Rhei Rhizoma Fraction B may be glycosides and tannins such as glucogallin, catechins, etc., since it has been reported that glucogallin and procyanidin have hypotensive effect on hypertensive rats. ${ }^{4,5)}$ Moreover, a similar effect of baicalein, which is baicalin aglycone and also one of main components of Scutellariae Radix, has been reported. $\left.{ }^{6}\right)$ We are now trying further fractionation from Scutellariae Radix Fraction B and Rhei Rhizoma Fraction B to ascertain a main substance(s) producing the hypotensive effect.

In isometric tension study in rat aorta, Rhei Rhizoma exerted a relaxant effect and Scutellariae Radix slightly exerted contractile and relaxant effects on endothelium-intact aorta, although the vasorelaxant effects of both medicines were small and produced at high concentrations. These vascular effects were not found in endothelium-denuded aorta. While, Coptidis Rhizoma had a significant relaxant effect on endothelium-intact and -denuded aorta at lower concentrations $(1-10 \mu \mathrm{g} / \mathrm{ml})$, in contrast to the result of Higasa et al. ${ }^{2)}$ that the vasorelxant effect was endothelium-independent. This is likely due to a difference in the dose of Coptidis Rhizoma or L-phenylephrine: they were examined the response to Coptidis Rhizoma of higher concentration range (100$600 \mu \mathrm{g} / \mathrm{ml})$ in rat thoracic aorta pre-contracted by high concentration of L-phenylephrine $(1 \mu \mathrm{M})$. The endothelium-dependent and -dependent vasorelaxant effects of Coptidis Rhi- 
zoma in this study are probably due to an activity of berberine. ${ }^{7)}$ The reason that Coptidis Rhizoma with such significant vasorelaxant activity had little effect on blood pressure in theophylline-treated rats is unknown. However, in any case, it is difficult to interpret the hypotensive effect of San'oshashin-to by their vasorelaxant effects. The hypotensive effect of Kampo medicines may not be mediated by the direct action on blood vessel but by other actions.

The hypotensive effects of Fraction B and Fraction C separated from San'o-shashin-to and Rhei Rhizoma were caused with a reduction in heart rate. It is well known that theophylline is a potent stimulant of the central nervous system and causes a release of endogenous catecholamines. It has been reported that Rhei Rhizoma has a psychotropic action by depression of noradrenergic and dopaminergic nerve activities, ${ }^{8)}$ and Scutellariae Radix has sedative actions by inhibition of adenylate cyclase activity. ${ }^{9)}$ Therefore, the hypotensive effect of San'o-shashin-to may be partially due to suppressions central nervous system and interference in release of endogenous catecholamines.

In conclusion, the present results suggest that the hypoten- sive effect of San'o-shashin-to is not mediated by the direct action on blood vessel but by other actions. Some components in Scutellariae Radix and Rhei Rhizoma, especially in the latter, but in Coptidis Rhizoma, may play a main role in the hypotensive effect.

\section{REFERENCES}

1) Sanae F., Komatsu Y., Amagaya S., Chisaki K., Hayashi H., Biol. Pharm. Bull., 23, 762-765 (2000).

2) Higasa K., Hatake K., Higasa M., Hishida S., J. Trad. Med., 9, 169174 (1992).

3) Sanae F., Hayashi H., Jpn. J. Pharmacol., 78, 345-354 (1998).

4) Hsu F. L., Lee Y. Y., Cheng J. T., J. Nat. Prod., 57, 308-312 (1994).

5) Cheng J. T., Hsu F. L., Chen H. F., Planta Med., 59, 405-407 (1993).

6) Takizawa H., Dellipizzi A. M., Nasjletti A., Hypertension, 31, 866871 (1998).

7) Ko W. H., Yao X. Q., Lau C. W., Law W. I., Chen Z. Y., Kwok W., Ho K., Huang H., Eur. J. Pharmacol., 399, 187-196 (2000).

8) Fujiwara M., Iwasaki K., Kurauchi K., Nishioka I., Nonaka G., Ueki A., J. Trad. Med., 3, 322-323 (1986).

9) Tohda M., Tohda C., Manabe I., Tandai Y., Shimizu M., Miyaichi Y., Tomimori T., Nomura Y., J. Trad. Med., 10, 179-185 (1993). 